\title{
EXPLORING THE ORIGINS OF BURNOUT AMONG SECONDARY EDUCATORS
}

\begin{abstract}
Authors:
Christian L. van Tonder ${ }^{1}$ Colette Williams ${ }^{1}$

Affiliations:

${ }^{1}$ Department of Industrial Psychology and People Management, University of Johannesburg, South Africa
\end{abstract}

Correspondence to: Christian L. van Tonder

e-mail:

chrisvt@uj.ac.za

\section{Postal address:}

Department of Industrial Psychology and People Management, PO Box 524, University of Johannesburg, Auckland Park, 2006, South Africa

\section{Keywords:}

exhaustion; Maslach

Burnout Inventory; stress; teaching staff; work experience

\section{Dates:}

Received: 19 Mar. 2009

Accepted: 19 Aug. 2009

Published: 21 Oct. 2009

How to cite this article: Van Tonder, C.L., \& Williams, C. (2009). Exploring the origins of burnout among secondary educators. SA Journal of Industrial Psychology/SA Tydskrif vir Bedryfsielkunde, 35(1), Art. \#762, 15 pages. DOI: 10.4102/sajip. v35i1.762

\section{This article is available} at: http://www.sajip.co.za

(C) 2009. The Authors. Licensee: OpenJournals Publishing. This work is licensed under the Creative Commons Attribution License.

\section{ABSTRACT}

Orientation: Maslach and Leiter (1997) have suggested that burnout constitutes an erosion of the soul. Burnout is a non-discriminatory phenomenon with a pronounced negative impact on the individual employee and the organisation and is particularly prevalent among educators.

Research purpose: This study aimed to explore the probable reasons for burnout among secondary educators.

Study motivation: Several South African studies have focused on the phenomenon of burnout among educators but the probable reasons for burnout in this population have not yet received adequate attention. This study extended earlier international research that probed this facet.

Research design, approach and method: A mixed-methods design with a predominantly qualitative methodology was employed to explore the probable reasons for burnout among 59 educators from three urban secondary schools in Gauteng, South Africa. Data comprised Maslach Burnout Inventory-General Survey protocols and rich data work descriptions. Semi-structured interviews were also conducted with the five participants who tested highest on the burnout indicators.

Main findings: The results indicated that a negative learner profile and workload were the most frequently cited reasons for potential burnout.

Practical/managerial implications: Burnout requires considered attention and aggressive contextspecific intervention to contain its negative impact on both the educator and the student learning experience.

\section{INTRODUCTION}

Burnout is a worldwide phenomenon of substantial significance that has a detrimental impact on employees at all organisational levels and on organisations in their entirety, which translates into substantial human and economic cost (Leiter \& Maslach, 2001; Maslach, 2001; Mirvis, Graney \& Kilpatrick, 1999; Toppinen-Tanner, Kalimo \& Mutanen, 2002). As such, burnout has become a crucial issue for all institutions that aim to produce quality products (Leiter \& Maslach, 2001) and services on a sustainable basis and to remain innovative in an increasingly competitive environment.

For many years, the phenomenon of burnout was viewed as a particular individual's problem, somehow related to some individual deficiency in personality, motive and/or conduct (Angerer, 2003). Subsequent research, however, has suggested that it originates in the individual's work environment (Burke \& Greenglass, 2001; Houkes, De Jonge \& Bakker, 2003) but it is far more complex than this and requires further consideration.

\section{The nature of burnout}

Although the term 'burnout' gained popularity largely through Greene's 1961 novel, A burn-out case, it had been used prior to this in both fictional and non-fictional writing to describe a state of excessive fatigue and a loss of idealism and passion for work (Maslach, Schaufeli \& Leiter, 2001, p. 398). At that stage, burnout was already recognised as a social problem substantially before it became the focus of systematic scholarly enquiry (Maslach et al., 2001, p. 398). Pioneering work in the scholarly domain was undertaken by Freudenberger in 1975 and Maslach in 1976 (Maslach et al., 2001, p. 399), with the former using the term to convey his own experience of depleted emotionality and loss of motivation and the latter observing the prominence of emotional stress and its implications for job behaviour during interviews with human-services workers.

Originally, burnout was equated with stress that arises from the persistent pursuit of success (Freudenberger, 1974). Freudenberger (1975) subsequently defined it as a state of physical and emotional depletion that develops from work conditions and that typically leaves the individual feeling exhausted and worn out and experiencing feelings of failure. Maslach (1982) argued that burnout was a syndrome exclusive to fields such as healthcare, teaching and human services and that it comprised emotional exhaustion, depersonalisation and diminished personal accomplishment. Subsequent research revealed that delimiting the phenomenon to 'people' professions was too restrictive and the definition was consequently broadened to include employees from different occupational groupings and levels (Hoops, 1999; Leiter \& Maslach, 2001; Schaufeli, Leiter \& Kalimo, 1995). Schaufeli and Enzmann (1998), for example, viewed burnout as a persistent and negative work-related state of mind that is characterised by exhaustion, a sense of diminished effectiveness, declining motivation and the development of dysfunctional work attitudes. This depiction of burnout highlights several basic parameters (Golden, Piedmont, Ciarrocchi \& Rodgerson, 2004): Burnout is first and foremost a phenomenon that has its origins in both situational and person factors, it occurs among 'normal' people and it translates into cognitive, affective and behavioural symptoms. This is an important perspective, as burnout was initially thought to be a problem residing entirely within a particular 
individual, i.e. the consequence of a deficiency in the personal profile of an individual (Angerer, 2003). This was later followed by a 'pendulum swing' towards the institutional setting as the origin where the causes of burnout are to be found and it was argued that it is essentially a phenomenon that emerges from work-setting causes (Burke \& Greenglass, 2001). The concurrent role and presence of both work setting and personal variables have since been recognised (Golden et al., 2004) and more integrative theoretical frameworks that explicitly incorporate both situational and individual factors in the development of burnout are emerging (Maslach et al., 2001).

More recently, Maslach et al. (2001, p. 399) described burnout as a psychological syndrome that develops in response to chronic emotional and interpersonal stressors in the work situation, which, de facto, articulates a non-productive relationship (effectively, a crisis) between employees and their work (Ahola et al., 2005; Leiter \& Maslach, 2001). From this perspective, burnout, in particular, appears to be indicative of a substantively dysfunctional work setting and organisation and it is consequently a comment on the work environment and institutional setting, more so than on employees.

In an attempt to clarify the parameters of the phenomenon, Leiter and Maslach (2001) proposed that burnout be considered as an extreme point on a three-dimensional continuum that comprises energy (exhaustion), involvement (cynicism) and effectiveness (professional efficacy). The majority of scholars (Ahola et al., 2005; Bakker, Van der Zee, Lewig \& Dollard, 2006; Maslach et al., 2001) have used the term burnout to capture the overall state brought about by the compound effects of, firstly, a sense of being emotionally spent and mentally and physically drained and of feeling overextended or overstrained (the exhaustion component of burnout). It incorporates, secondly, an aloof, detached and often negative, indifferent and callous attitude (or response) towards various aspects of the work situation, which also manifests in a lack of enthusiasm and disengagement from work (the cynicism and/or depersonalisation component). In the final instance, burnout includes a perceived or experienced lack of accomplishment and diminished productivity accompanied by feelings of incompetence (the personal efficacy component). In essence, exhaustion is viewed as the depletion of the person's mental resources, while cynicism is considered a mental distancing from the person's work and professional self-efficacy as the person's beliefs about his/her effectiveness and accomplishment at work. The fundamental dynamic is one that stipulates that those who register high levels of burnout experience mental and physical exhaustion and distance themselves from their work.

Burnout is characterised by an assortment of psychological (cognitive and affective), physical and behavioural symptoms, and as many as 100 different symptoms have been identified (Botha, 2006). These symptoms can include low energy and chronic fatigue, insomnia, recurrent flu spells and colds, infections, digestive problems, dizziness, nausea, allergies, skin problems, breathing difficulties, stiffness and muscle aches, back pains and headaches, depression, substance abuse, loss of concentration, problematic interpersonal relations and low self-esteem (Angerer, 2003; Brock \& Grady, 2000; Maslach \& Jackson, 1981; Pines, 1993). Schaufeli and Buunk (2005) have since categorised burnout symptoms into five categories. These include affective manifestations (gloomy depressed mood, aggression and anxiety), cognitive manifestations (feelings of hopelessness, helplessness and powerlessness, a sense of failure, poor job-related esteem, impotence, impaired cognitive skills such as memory and attention, negativism, pessimism, reduced empathy, distrust and an exceptionally critical attitude towards management, peers and supervisors), physical manifestations (regular bouts of flu, somatic complaints, higher levels of cortisol and cholesterol and coronary heart disease), behavioural manifestations (substance abuse, absenteeism, staff turnover and impaired work performance) and motivational manifestations (a decline in and/or loss of enthusiasm, interest, idealism and zest, disillusionment, disappointment, resignation and submission, interpersonal conflicts and physical and mental withdrawal). These symptoms apply to managerial and non-managerial employees, with low energy and lack of commitment probably more salient symptoms of leaders with significant burnout (Mirvis et al., 1999).

Even though burnout has been conceptualised as a form of job stress (Maslach, 2001) that appears to be a more severe version developing from prolonged exposure to stress (Botha, 2006; Kittel \& Leynen, 2003), the precise relationship between these constructs is not entirely clear. The relatedness (not causality) of occupational or job stress to burnout, for example, has been observed among professionals in more stressful positions (Jamal \& Baba, 2000) and among hospitality-industry employees (Gill, Flaschner \& Shachar, 2006). In both instances, occupational and job stress was positively related to burnout. McManus, Winder and Gordon (2002), in a study of UK doctors, however, found that stress and burnout stand in a causal cycle where stress increases emotional exhaustion, which, in turn, increases stress, which then again increases emotional exhaustion. Even though these observations serve only to confirm the intertwined relationship of the constructs and do not, as yet, provide adequate clarity on their relatedness, they do, nonetheless, provide some legitimacy for researchers who tend to use the concepts in unison.

Given the extensive array of symptoms recorded for burnout, it is not surprising that it is often also associated with anxiety and depression (McManus et al., 2002). Overlaps have, in fact, been recorded between burnout and disorders such as chronic fatigue syndrome, fibromyalgia and major depression (Sandström, Rhodin, Lundberg, Olsson \& Nyberg, 2005). Several recent studies that employed the Maslach Burnout Inventory (MBI) and several measures of depression, however, have clearly distinguished between these constructs (Bakker et al., 2000; Maslach et al., 2001). Whereas depression is multifaceted, burnout is specific to work content (Angerer, 2003) and is revealed in work-related symptoms rather than physical and biological symptoms (the latter being more salient in anxiety and depression). This is consistent with Angerer's (2003) observation that mental and behavioural symptoms are, in most burnout cases, more prevalent than physical symptoms.

When we turn to the typical antecedents and causes of burnout, an impressive number of studies has revealed a plethora of factors contributing to or causing stress and burnout (Taris, Van Horn, Schaufeli \& Schreurs, 2004). Substantial consistency is observed across occupational groupings and professions (such as those of the Methodist clergy, police officers, medical doctors, information technology specialists, managers and clinical social workers) other than educators, and across geographical (i.e. national) boundaries (Golden et al., 2004; Griva \& Joekes, 2003; Loo, 2004; McManus et al., 2002; Mirvis et al., 1999; Richardsen \& Martinussen, 2004; Tang, Au, Schwarzer \& Schmitz, 2001; Toppinen-Tanner et al., 2002; Um \& Harrison, 1998).

The consequences of burnout are substantial and span the individual's home and work settings (Burke \& Greenglass, 2001). In the work situation, these may include the intention to quit, high actual staff turnover, absenteeism, low morale and reduced job satisfaction (Angerer, 2003; Golembiewski, Hilles \& Daly, 1987; Maslach \& Jackson, 1981; Pines, Aronson \& Kafry, 1981; Um \& Harrison, 1998). Moreover, while many studies have reported a relationship between heart attacks and burnout (Angerer, 2003), the phenomenon has also been linked to physical exhaustion and illness, family and marital conflict and the increased use of alcohol and drugs (Koeske \& Koeske, 1989). The development of psychological problems is equally probable (Maslach \& Jackson, 1982). Health issues, such as sleeplessness and depression, are common consequences of burnout that negatively impact on the employee's work performance and commitment which, in turn, result in lowered performance and productivity (Burke \& Greenglass, 1991; Gill et al., 2006; Levinson, 1996). 
Contemporary perspectives on burnout have begun to explore the 'positive antithesis of burnout' or work engagement (Maslach et al., 2001, p. 397), which seemingly represents one end of a bipolar scale, with burnout representing the opposite end. While burnout refers to a human state that is characterised by feelings of ineffectiveness, exhaustion and distancing from work and people, work engagement constitutes a reversal of this state, where people feel energised and involved with work and people. Maslach et al. (2001), however, indicated that different approaches to the conceptualisation of work engagement are being explored (by, for example, Schaufeli and others) and that engagement is not necessarily presumed to be assessed by a reversal of the MBI scoring profile.

Another important development in the field of burnout research relates to increasing focus on the systemic nature and role of burnout and, in particular, its organisational role and impact. At the organisational level, burnout similarly has pronounced consequences. Work is generally performed by employees in some organisational setting (Cherniss, 1980; Um \& Harrison, 1998) characterised by specific role and regulatory structures (and authority and power) that invariably contribute to job stress and burnout (Cherniss, 1980; Um \& Brown-Standridge, 1993). Bhanugopan and Fish (2006) consequently related burnout to the discrepancy between the expectations held by individuals of how they meet role responsibilities and expectations implied or imposed by the existing organisational structure. When pressure for improved performance intensifies or is maintained for long periods (an overriding concern in current times), stress arising from this results in exhausted and burnt-out employees (Messmer, 2004, p. 12). Mirvis et al. (1999) also observed that burnout among organisational leaders, in particular, has a pronounced effect on the organisation at large. It firstly results in ineffective management and secondly (more indirectly) facilitates the transfer of the burnout stage(s) to colleagues and to the organisation (Golembiewski \& Boss, 1991).

It seems clear that burnout is a non-discriminatory phenomenon that is prevalent not only in all occupations and and professions, but also invariably has a pronounced negative impact on the employee and the organisation. The view by Maslach and Leiter (1997) that burnout '. . . represents an erosion in values, dignity, spirit, and will, an erosion of the human soul' (p. 17) offers an appropriate concluding perspective on the nature of the burnout phenomenon. It suggests that employers should give substantial and careful consideration to the phenomenon.

\section{Burnout among educators}

Several scholars have argued that burnout is more prevalent among educators and more relevant to teaching than any other professional arena (Antoniou, Polychroni \& Vlachakis, 2006; Friedman, 1991; Griva \& Joekes, 2003; Hughes, 2001). Burnout is indeed a phenomenon that is regularly suffered by educators (Burke \& Greenglass, 1996; Cherniss, 1980; Hughes, 2001; Kittel \& Leynen, 2003; McCormick, Ayres \& Beechey, 2006) and it is clear that educators experience a great deal of stress and burnout practically on a daily basis (Griva \& Joekes, 2003; Jackson \& Rothmann, 2005a). The impact of this on educators' mental and physical health is decidedly negative (Antoniou et al., 2006; Pomaki \& Anagnostopoulou, 2003; Tang et al., 2001) and may lead to psychological dysfunction (Griva \& Joekes, 2003). Consequently, stress and burnout among educators have received considerable research attention across the globe (Antoniou et al., 2006; Griva \& Joekes, 2003; Jackson \& Rothmann, 2005a, 2005b; Kittel \& Leynen, 2003; McCormick et al., 2006; Pomaki \& Anagnostopoulou, 2003; Pretorius, 1994; Sari, 2000, 2002, 2004; Stevenson \& Harper, 2006; Tang et al., 2001; Travers \& Cooper, 1993, 1996).

The stress that educators experience has equally undesirable consequences for their immediate work environment. It directly affects the learning environment and interferes with the achievement of educational goals (Tang et al., 2001). The 'burnt-out' teacher is also bound to have a negative effect on the well-being and performance of students. Burnout could furthermore lead to teacher absenteeism, alienation, detachment and eventually teachers abandoning the profession (Maslach \& Leiter, 1997). These perspectives would suggest that it is important for and in the interest of the education profession to consider the role and prevalence of burnout among educators in South Africa.

\section{Burnout among educators in South Africa}

The South African educational landscape has experienced significant changes over the past decade, which could contribute to higher levels of stress and burnout among educators. Jackson and Rothmann (2005a) indicated that the South African education system accommodates more than 12.3 million learners, 29386 primary and secondary schools, 375000 educators, 5000 inspectors and subject advisers and 68000 officials, managers and support personnel. While several efforts have been made to improve education in South Africa, the effectiveness of educators is still influenced by racism, violence and other manifestations of antisocial behaviour in schools (Jackson \& Rothmann, 2005a). Practically on a daily basis, educators in South Africa have to deal with classes with large numbers of students (40 to 60) and with outcome based education (OBE), which was introduced in 2000 and which increased the workload of educators immensely. Several studies have moreover confirmed that anxiety, depression, job dissatisfaction and burnout, with the accompanying physical-health consequences, are pronounced experiences of today's educators (Pomaki \& Anagnostopoulou, 2003; Sari, 2004). Educators in South Africa are not exempt from these negative outcomes (Jackson \& Rothmann, 2005a). This suggests the importance of attending to the well-being of the teacher corps in South Africa and, more specifically, paying attention to the effects that stress and burnout have on these teachers.

By and large, studies on educator stress and burnout have tended to focus on developed English-speaking countries and little is known about the experiences of educators in developing countries (Tang et al., 2001). In South Africa, most of the research on burnout in the schooling system has been undertaken in the North West Province (Jackson \& Rothmann, 2005b). The focus of this research, which has predominantly been quantitative in nature, has been essentially to establish the psychometric properties of an adapted version of the MBI General Survey (GS) in a South African setting with educators of different language groups. These studies have revealed that the levels of exhaustion, mental distancing and professional efficacy experienced by educators differ substantially from school to school (Jackson \& Rothmann, 2005b).

In countries other than South Africa, burnout research has directed meaningful attention to the reasons for burnout among educators. In South Africa, however, the reasons for burnout among educators have not yet been adequately explored. The reasons for this remain speculative but it seems that the choice of research objectives and approaches may have been influenced by a tendency towards more quantitative studies, which may account for the absence of exploratory studies. The limitations of burnout research in South Africa furthermore include poorly designed and controlled studies and a lack of sophisticated statistical analyses (Rothmann, 2003).

\section{Sources of educator burnout}

With this study's focus on the sources of educator burnout, it is useful to note that a plethora of sources has been identified in international literature. These sources emerge equally from the work setting and context and from the individual's psychological and physiological profile. Sources of burnout originating in the work context that have been reported include workload and work pressure, unsatisfactory working conditions, poor 
relationships with colleagues and superiors, unsatisfactory school management and administration, the form and content of school cultures, school structure and communication, leadership practices, a lack of promotional prospects, resources available to schools, the size of classes, educational policies and procedures, school reputation, relationships with the community and with parents, and pupil attitudes and behaviour (Antoniou et al. 2006; Clarkson \& Hodgkinson, 2007; Griva \& Joekes, 2003; Kittel \& Leynen, 2003; Oshagbemi, 2000; Sari, 2000, 2005; Zeffane \& McLoughlin, 2006). Institutional and societal factors, such as low pay, poor training, a lack of resources, a lack of teaching and learning materials and a breakdown in traditional support systems, can be added to this list (Burke \& Greenglass, 1996; Sari, 2002). In addition to their work pressure, the emotional, mental and physical reactions of educators also contribute to stress (Sari, 2004), while feelings of low status and gender have been found to be related to burnout (Antoniou et al., 2006; Clarkson \& Hodgkinson, 2007; Sari, 2000). Apart from these sources of stress and burnout, the level of interaction of educators with students and colleagues, access to new and/or professional knowledge, opportunities and challenges, working conditions (including salary), advancement opportunities and job security are also considered meaningful predictors of burnout (Dinham \& Scott, 2000; Ratliff, 1988; Sari, 2004). Several demographic variables have also been found to be related to burnout and these include age, marital status and gender (Maslach, 1982) but the results have not been conclusive or necessarily consistent across the studies. Age is a case in point, with a study by Calvert, Flynn, Fraser and Long (1991) failing to produce a significant relationship between age and burnout. More recently, a study by Xanthopoulou et al. (2007) revealed overwhelming job demands to be one of the strongest predictors of burnout.

Against this setting, the current study intends to explore the reasons why educators at secondary schools in Gauteng are likely to experience burnout. This aligns with the views of those who have argued that burnout among academic-faculty members is a phenomenon of growing proportions and in need of further research (Barkhuizen \& Rothmann, in press). Exploring the underlying reasons for burnout will assist with the search for more effective strategies for managing and containing the incidence of burnout among educators. The operational objectives of this study are therefore to measure and establish the incidence of burnout among a selection of educators and to identify the potential reasons for burnout in those educators who scored the highest according to the burnout instrument. The design and methodology for a study to address these research objectives are presented under 'Research design'.

\section{RESEARCH DESIGN Research approach}

This study's design fitted that of a mixed-methods approach, as it embraced elements of both qualitative and quantitative methodologies, although the qualitative focus was, in fact, dominant. Technically, the study's design can be conceptualised as a dominant - less dominant mixed methods design (cf. Tashakkori \& Teddlie, 1998, p. 45), as the quantitative and qualitative methodologies were not utilised in equal proportions. This follows from the exploratory purpose of data analysis (Onwuegbuzie \& Teddlie, 2003), hence the prominence of the qualitative component.

The choice of a mixed-methods design followed, largely, from the manner in which burnout was conceptualised. At the same time, the design should overcome the implicit bias that stems from single-method, single-observer, single-theory studies (Rocco, Bliss, Gallagher \& Perez-Prado, 2003). Mixed-method studies are informed by several paradigms, typically the positivist (with quantitative-research methodologies) and the interpretative (with qualitative methodologies) paradigms. Reality, knowledge and experience are very different for these two fundamental paradigms and, as a result, defining and measuring phenomena similarly take very different forms.

Positivist studies require precise quantitative data to reveal relevant 'laws' with which to understand (predict) behaviour. These are obtained through data-gathering methodologies, such as experiments, surveys and statistics (Newman, 2000). Positivist studies are a paradigm largely premised on the philosophy of science as embodied in the natural sciences and are applied to research in the social sciences. The physical and the social world and therefore knowledge of human functioning are seen as existing externally to the researcher (Denzin \& Lincoln, 1994; Newman, 2000). This reality, it is argued, is patterned and has regularity (Terre Blanche \& Durrheim, 2002, pp. 3-8). Consistent with this positivist tradition, burnout is viewed as a patterned and recurring phenomenon that is measurable with established, i.e. reliable, and validated surveys (such as the MBI-GS). A more quantitative approach is therefore appropriate for establishing the levels of burnout among secondary educators.

The second design component of a mixed-methods study is informed by the interpretative paradigm, which is often combined with social constructivism (Creswell, 2003; Esterberg, 2002). This approach takes the position that socially ascribed meaning is the

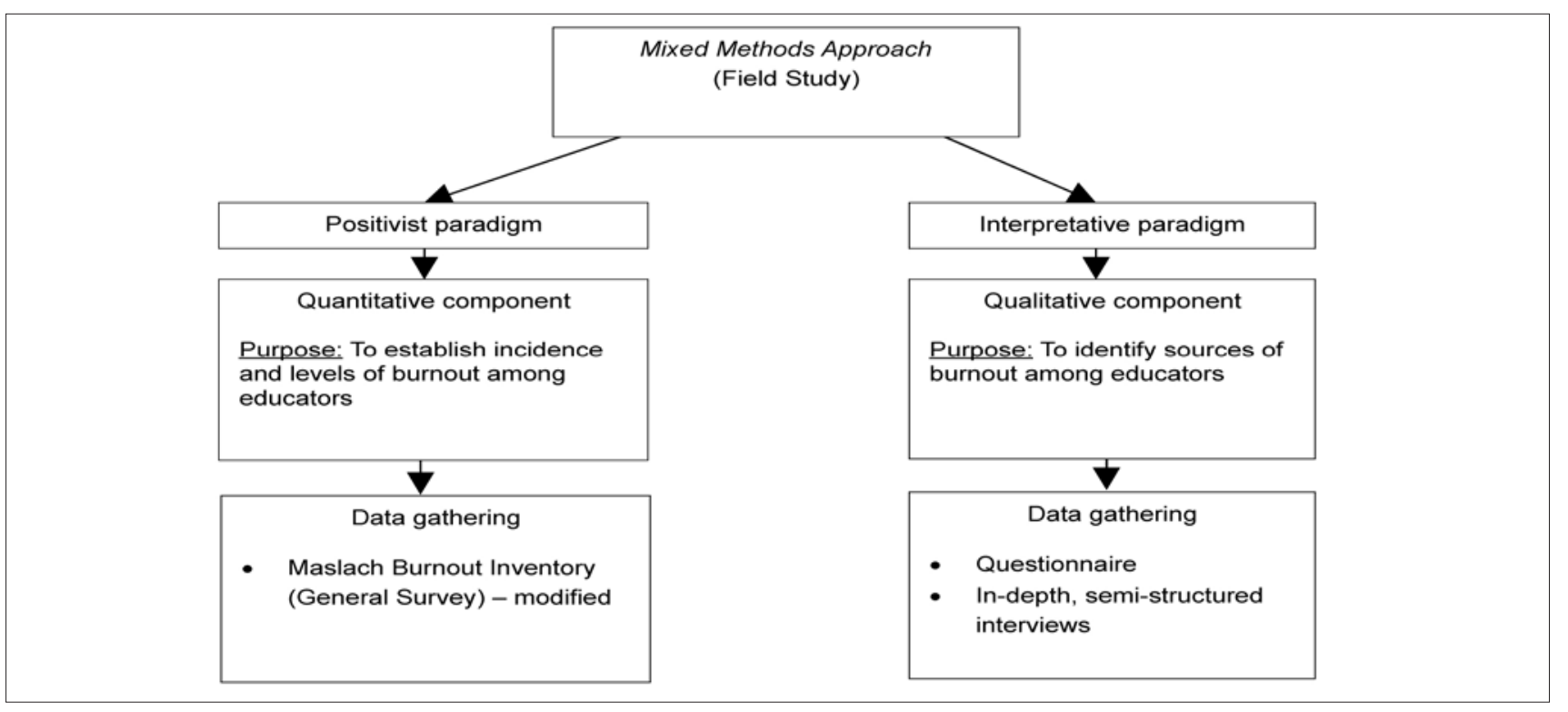

FIGURE 1

Research design and methodology 
TABLE 1

Participant demographics

\begin{tabular}{|c|c|c|c|c|c|c|c|c|c|c|c|c|c|c|}
\hline \multicolumn{3}{|c|}{ AGE (YEARS) } & \multicolumn{3}{|c|}{ TENURE (YEARS) } & \multicolumn{3}{|c|}{ MARITAL STATUS } & \multicolumn{3}{|c|}{ LANGUAGE } & \multicolumn{3}{|c|}{ QUALIFICATION } \\
\hline CATEGORY & $f$ & $\%^{a}$ & CATEGORY & $f$ & $\%$ & CATEGORY & $f$ & $\%$ & CATEGORY & $f$ & $\%$ & CATEGORY & $f$ & $\%$ \\
\hline$>25$ & 3 & 5.08 & $<2$ & 10 & 16.94 & Not married & 9 & 15.25 & Afrikaans & 38 & 64.40 & B degree & 22 & 37.28 \\
\hline $26-30$ & 8 & 13.55 & $2-5$ & 19 & 32.20 & Living: partner & 2 & 3.38 & English & 11 & 18.64 & Honours & 7 & 11.86 \\
\hline $31-35$ & 9 & 15.25 & $6-10$ & 9 & 15.25 & Married & 44 & 74.57 & Northern Sotho & 4 & 6.77 & 4-year diploma & 20 & 33.89 \\
\hline $36-40$ & 3 & 5.08 & $11-15$ & 13 & 22.03 & Divorced & 2 & 3.38 & Tsonga & 3 & 5.08 & 3-year diploma & 10 & 16.94 \\
\hline $41-45$ & 18 & 30.50 & $16+$ & 8 & 13.55 & Single & 1 & 1.69 & Tswana & 3 & 5.08 & & & \\
\hline $46-50$ & 7 & 11.86 & & & & Widow/er & 1 & 1.69 & & & & & & \\
\hline $51-55$ & 7 & 11.86 & & & & & & & & & & & & \\
\hline $56-65$ & 4 & 6.77 & & & & & & & & & & & & \\
\hline TOTAL & 59 & 100.00 & & 59 & 100.00 & & 59 & 100.00 & & 59 & 100.00 & & 59 & 100.00 \\
\hline
\end{tabular}

${ }^{a}$ The row of percentages reflects the proportions of the overall sample (59 respondents or $100 \%$ ) defined in terms of a specific categorical variable (indicated in the column headed 'Age'). For example, ten educators have less than two years service (see the column headed 'Tenure'), amounting to $16.94 \%$ of the total sample of 59 educators.

actual reality and that the subjective experience of a person is real and holds the key to understanding phenomena. Terreblanche and Kelly $(1999$, p. 68) summarised this paradigmatic approach when they stated that interpretive research use[s] methods that try to interpret and describe people's feelings and experiences in human terms rather than through quantification'. It follows that the advancement of scientific knowledge implies interacting with and listening to people to obtain a complete understanding. Accordingly, true meaning can be discovered only through a detailed study of the narrative or text/transcript of research participants (Denzin \& Lincoln, 1994; Newman, 2000) derived from a situated activity where the researcher is in, and not outside, the world (Denzin \& Lincoln, 2005, p. 3).

These two paradigms interlock in the conceptualisation of burnout for the purposes of this study. As indicated earlier, burnout is (ontologically) believed to be a discernable and measurable phenomenon of generally known parameters, i.e. it is possible to measure and detect noticeable and consistent patterns in the phenomenon at a general level. At the same time, it is also believed that the nature and onset of stress and burnout, for any person, are uniquely individual and a function of a variety of factors, including how a person perceives, interprets and internalises the meaning of situations. From this perspective, it follows that the epistemology of burnout should straddle both paradigms and that knowledge of the phenomenon should be both objectively and subjectively discernible. Methodologically, knowledge of burnout and, specifically, of the levels and incidence of burnout can be accessed (normatively) through quantitative assessment (such as the MBI-GS), while the origins and sources of burnout can be established through qualitative procedures (such as semi-structured interviews).

\section{Research strategy}

Being a mixed-paradigm study, a field-study approach that incorporates, firstly, a survey (the MBI-GS) and, secondly, semi-structured and in-depth interviews was considered to be appropriate (Figure 1). The field-study approach ensured that currently employed educators were engaged in their work situations at a given time. Such a strategy, moreover, allowed access to several respondents in order to establish the prevalence of the phenomenon of burnout, yet also provided the opportunity to explore the nature and reasons of the phenomenon in greater depth with a smaller group of respondents who were part of the original sample. The MBI-GS revealed the educators who were scoring high and low on the indicators of burnout, while the semi-structured interviews provided rich data on the educators' perceptions, feelings and experiences, from which the reasons for the phenomenon were extracted.

\section{Research method}

Research setting

Secondary (high) schools located in the greater Johannesburg area (Gauteng province) provided the opportunity for pursuing the research objectives of this study, in particular as burnout is a noted phenomenon among educators worldwide. As indicated, burnout among educators has received extensive research coverage in international settings. In South Africa, the education system has been the subject of pervasive change and is the regular subject of media coverage. Schools located in Gauteng and greater Johannesburg, more specifically, tend to be better resourced than rural schools, which should reduce the influence of resources as potential stressors and causes of burnout.

\section{Sampling}

The research population for the study was defined as all Gauteng secondary-school educators. Through convenience sampling, the participation of three secondary schools was secured. This study attempted to maximise participation and all the educators in the three schools were consequently approached to participate. This comprised a potential sample of 65 educators, of which 59 $(90.7 \%)$ eventually participated. The basic demographic features of the participating educators are conveyed in Table 1.

From Table 1, it is clear that the sample across the three schools comprised more female educators $(69.4 \%)$ than males $(30.6 \%)$, with the majority of respondents occupying the rank of 'educator' (54 educators or $91.5 \%$ ). The educators were well qualified, with most possessing a three-year post-school qualification or higher.

\section{Methods of data gathering}

To address the first research objective of this study (the quantitative component), the GS version of the MBI was selected to identify the incidence and levels of burnout among the educators in the sample. The MBI was developed by Maslach and Jackson (1981) and is currently the most widely used measure for burnout (Angerer, 2003; Moore, 2000). It is the only measure of burnout that measures all three core dimensions of burnout, namely exhaustion, depersonalisation and personal efficacy (Maslach et al., 2001).

Originally, the MBI Educators Survey (ES) comprised the three dimensions of emotional exhaustion, depersonalisation and personal efficacy. Maslach's (2001) elaborated definition of burnout, which allowed for all occupations and not only for education, however, posed a problem for occupations that were not people-orientated to the same extent. As depersonalisation refers to a social relationship, it could not be expanded to work in general. To overcome this problem, the MBI-GS, in which depersonalisation was considered a special case of mental distancing, was developed (Jackson \& Rothmann, 2005a). The only differences between the two versions were that the cynicism scale in the MBI-GS was substituted in the MBI-ES with the depersonalisation scale and that, rather than using the term 
TABLE 2

Mean scores and standard deviations on sub-dimensions of the MB

\begin{tabular}{|c|c|c|c|c|c|c|c|c|c|}
\hline \multirow[b]{2}{*}{ VARIABLE } & \multirow[b]{2}{*}{$N$} & \multicolumn{2}{|c|}{ EXHAUSTION } & \multicolumn{2}{|c|}{ PERSONAL EFFICACY } & \multicolumn{2}{|c|}{ CYNICISM } & \multicolumn{2}{|c|}{ DEPERSONALISATION } \\
\hline & & $M^{a}$ & $S D$ & $M$ & $S D$ & $M$ & $S D$ & $M$ & $S D$ \\
\hline School A & 16 & 18.55 & 4.62 & 22.35 & 5.04 & 15.10 & 4.23 & 13.25 & 5.67 \\
\hline School B & 23 & 17.04 & 6.10 & 23.39 & 3.56 & 15.39 & 4.04 & 12.26 & 5.44 \\
\hline School C & 20 & 21.43 & 5.28 & 21.62 & 4.76 & 17.75 & 4.80 & 13.94 & 5.28 \\
\hline Female & 41 & 18.32 & 5.92 & 22.24 & 3.90 & 16.34 & 4.63 & 12.93 & 5.85 \\
\hline Male & 18 & 19.72 & 4.84 & 23.28 & 5.48 & 15.00 & 3.74 & 13.33 & 4.45 \\
\hline Overall & 59 & 18.75 & 5.61 & 22.56 & 4.42 & 15.93 & 4.39 & 13.05 & 5.43 \\
\hline
\end{tabular}

a The differences among the means of the different groups (schools or gender) are generally small. Visual inspection indicates that these are more substantive for exhaustion and cynicism for School C than Schools A or B. Only the difference between Schools $\mathrm{C}$ and $\mathrm{B}$ for exhaustion was statistically significant and practically meaningful $(t[37]=2.33, p=0.02, d=0.83$ ). Cohen's $d$ (index of effect size), calculated with the formula $d$ (difference) between the means of two groups $\left(\mathrm{M}_{1}-\mathrm{M}_{2}\right)$ and divided by the standard deviation ( $\sigma$ ) of either group is considered small when ranging between 0.20 and 0.50 , medium when between 0.50 and 0.80 and large when between 0.80 and above (Cohen, 1988; Valentine \& Cooper, 2003). An effect size of $d$, $=0.80$ is generally considered practically meaningful. Differences between males and females for each of the burnout dimensions proved insignificant.

'students' (in the MBI-ES version), the MBI-GS version used the term 'recipients'. Since then, the MBI has been expanded and now consists of three versions, namely the MBI Human Services Survey (HSS), the MBI-ES and the MBI-GS (Angerer, 2003). Of these, the MBI-GS is currently considered an equivalent but more widely applicable version of the MBI (Barnett, Brennan \& Gareis, 1999, p. 66).

For the purpose of the current study, the MBI-GS version was used to measure exhaustion, cynicism and professional efficacy, which, cumulatively, comprised 16 items (Schaufeli, Leiter, Maslach \& Jackson, 1996). Barkhuizen and Rothmann (in press), however, questioned whether it is possible to conceptualise academic burnout when it is measured with the MBI-GS, which omits the interpersonal dimension of depersonalisation. To overcome this problem in the current study (involving educators), the depersonalisation scale of the MBI-ES, which consists of five items, was added to the MBI-GS, as suggested by the authors. The only modification was to replace the word 'recipient' (MBI-GS) with 'student' (as it occurred in the MBIES). For this study, the participants were asked to respond to 21 items as opposed to the standard 16 of the MBI-GS.

The participants indicated their responses on a scale ranging from ' 0 ' ('never occurs') to ' 6 ' ('occurs daily') and were regarded as approaching burnout when they obtained high scores for exhaustion and cynicism or depersonalisation and low scores for professional efficacy. Local studies on the MBI have confirmed a three-factor structure and have consistently revealed good internal consistency (Storm \& Rothmann, 2003). These ranged from 0.87 to 0.89 for exhaustion, from 0.73 to 0.84 for cynicism and 0.76 for professional efficacy (Maslach, Jackson \& Leiter, 1996). A Cronbach alpha coefficient of 0.79 has reportedly been obtained for the depersonalisation scale (Jackson \& Rothmann, 2005a, in reference to Maslach \& Jackson, 1981). Internal consistencies with a similar magnitude have been recorded in the South African context (Rothmann \& Jansen van Vuuren, 2002). Storm and Rothmann (2003) moreover confirmed the cross-cultural efficacy of the MBI for different race and language groups.

The MBI-GS was consequently considered a suitable instrument for establishing the incidence and level of burnout among the sample of secondary educators engaged in this study.

Data gathering in terms of the second objective of this study (the qualitative component) focused on the likely reasons for burnout among the educators. This was accomplished with a short questionnaire that included biographical data and a single open-ended question that required educators to provide a short description of how they experienced their work.

For the purposes of this study, in-depth semi-structured interviews (Wengraf, 2001) were conducted with the five participants who tested highest for burnout, i.e. whose scoring profile fitted the established pattern for the burnout syndrome ${ }^{1}$ These interviews represented a more natural form of interacting with people (compared to questionnaire completion or participation in experimental settings) and consequently fitted the interpretative approach to research very well (Terre Blanche \& Durrheim, 1999). The interviews were video-recorded and the narratives were transcribed verbatim. A semi-structured, open-ended question, which wasformulated as follows, was asked in the interviews: 'How do you feel about and experience your job?' In the case of unresponsive respondents, a more directive questionwasasked:'Doyouenjoy coming toworkeverymorning?'

\section{Procedure}

Permission to conduct the study was sought from the school managers (the principals or deputy principals) of the three secondary schools. The purpose of the study was explained in a covering letter to the school managers and again during the oneon-one follow-up meetings with these officials. During these meetings, it was pointed out that participation was voluntary and that information would be treated in the strictest of confidence. The school managers then informed their staff of the research. An opportunity to administer the MBI was scheduled at a convenient time for the educators, after which the MBI and the short questionnaire were administered in a single collective session in the staff rooms. The educators were informed that ad hoc interviews would be conducted with a few participants to clarify data obtained from the MBI and the short questionnaire and that these would be arranged with the relevant participants. After the MBI was scored, the participants scoring highest in terms of burnout were identified and the interviews were conducted (and recorded) as per agreed arrangement at a location and time convenient to them. The interviews were then transcribed and the key themes were extracted through basic content analysis.

\section{Analysis of data}

In the absence of MBI norms for South African school educators, the educators who scored highest on the MBI sub-dimensions of exhaustion, cynicism and depersonalisation yet also revealed a tendency to score low on personal efficacy were identified as possible burnout candidates.

The responses to the open-ended question, which required a written response from the respondents, and the data obtained during the interviews with the selected respondents were subjected to content analysis. Basic content analysis and coding procedures were employed to identify the different data categories and themes. An open-ended approach to coding (an evolving code-book) that allowed the categories to emerge from the data was used. The unit of analysis to be coded was the basic

1.High scores for exhaustion and cynicism and low scores for professional efficacy are considered indicative of burnout (cf.Toppinen-Tanner et al., 2002). Others argue that high scores for the exhaustion and cynicism scales are sufficient to indicate burnout (Montgomery, Panagopolou, De Wildt \& Meenks, 2006). 
phrase (not a sentence). Two independent researchers compiled the code-book and discrepancies between researcher codes were resolved through consensus, resulting in a single code-book. A value of one (' 1 ') was allocated to every occurrence of a specific category code and the frequencies were calculated per code, after which themes were inductively derived from inspection of the code frequencies per category.

\section{FINDINGS Maslach Burnout Inventory (MBI)}

The mean scores on the subscales of burnout for the different categories of participants are summarised in Table 2. Potential participant scores on each of the burnout subscales typically range between 5 and 30 for exhaustion, cynicism and depersonalisation and between 6 and 36 for personal efficacy. Observed differences in burnout levels between the male and the female educators were negligible $(t[57]=-0.88, p=0.38 ;-0.82$, $p=0.41 ; 1.08, p=0.28$; and $-0.26, p=0.79$ for exhaustion, personal efficacy, cynicism and depersonalisation, respectively). The relatively high scores recorded for personal efficacy indicated that, on average, neither the males nor the females suffered from burnout at the time that the MBI was administered. Minor variations in scores on the other subscales were recorded for the females and the males.

The results also indicated that none of the staff complements of the three secondary schools could be characterised as burnt out. Only a few educators' individual scores approached a situation of burnout. Table 2 reveals minor differences among the schools, with School $C$ scoring highest on exhaustion $(M$ $=21.44, S D=5.28)$ and cynicism $(M=17.75, S D=4.80)$ and with School B scoring highest on personal efficacy $(M=23.39$,
$S D=3.56)$. The levels of exhaustion reported at School $C$ compared to those at School B $(t[37]=2.33, p=0.02, d=0.83)$ were significantly higher and practically meaningful. Although the remainder of the differences among the three schools on the reported levels of exhaustion, personal efficacy, cynicism and depersonalisation were not significant, higher levels of cynicism at School C compared to School A $(t[34]=1.76, p=$ $0.08, d=0.55)$ and School B $(t[37]=1.66, p=0.10, d=0.49)$ were approaching practical meaningfulness. This was also true for the higher levels of reported exhaustion at School $C$ compared to School A $(t[34]=1.74, p=0.08, d=0.54)$. The differences between School $\mathrm{C}$ and the other schools suggest that the management of the phenomena of stress and burnout should probably receive more attention at this school. The scores on depersonalisation were low for all the schools. In summary, no actual incidence of burnout was observed but the scores did veer in the direction of burnout, with a few individuals appearing to be candidates for burnout. It is important to note that burnout is not a shortlived phenomenon. A study by Mirvis et al. (1999) revealed that the syndrome progressively worsens over time and noted that a significant proportion of employees initially categorised as lowburnout candidates eventually transitioned to high-burnout stages some eight years later.

\section{Text analysis (short questionnaire)}

The brief questionnaire (comprising biographical items and a single open-ended question) requested the participating educators to provide a short descriptive account of how they currently experience their work. From the narratives provided by the educators, 164 phrases were identified and subjected to content analysis. Codes were allocated to each phrase and repeated when an educator mentioned the same fact or commented about

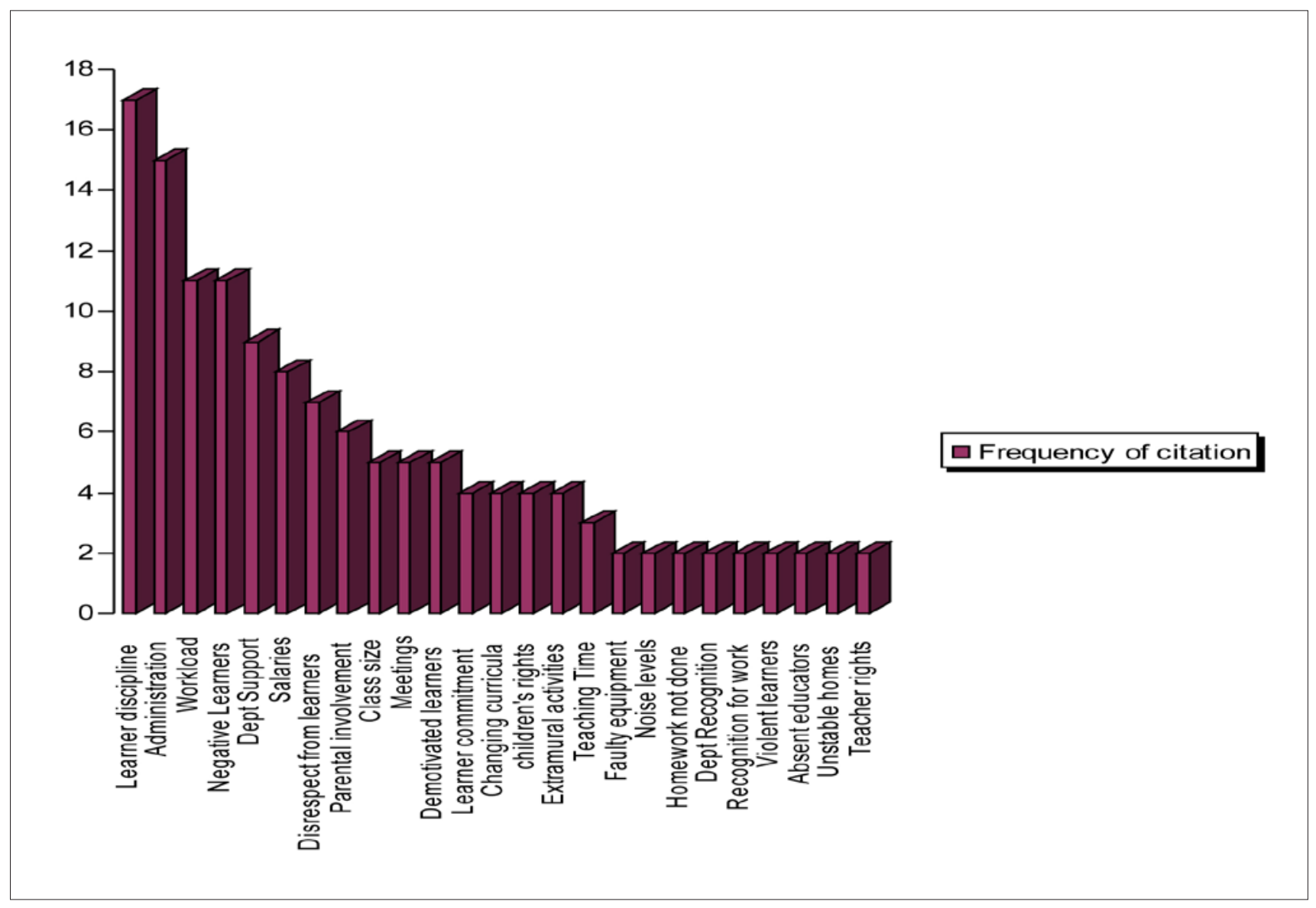

FIGURE 2

Text analysis: Frequency of reported work concerns 
TABLE 3

Themes indicating probable sources of stress and burnout among educators (text analysis)

\begin{tabular}{|c|c|c|}
\hline THEME (SOURCE) OF BURNOUT & ILLUSTRATIVE VERBATIM EXCERPTS FROM EDUCATORS & NO. OF RESPONSES \\
\hline Learner profile (attitude and behaviour) & $\begin{array}{l}\text { 'to struggle with discipline', 'spent the majority of the time disciplining learners', 'fail to provide alternative } \\
\text { measures for ill disciplined kids'(*), 'children are a lot less disciplined', 'learner commitment', 'learners } \\
\text { are rude and have no proper upbringing', 'difficult learners, they are ill mannered and rude', 'a don't care } \\
\text { attitude', 'bad learner behaviour', 'disrespect from learners', 'learners don't do homework' } \\
\text { 'learners' interpersonal skills', 'low level of education on primary level', 'drugs and alcohol abuse', ' use of } \\
\text { cell phones', 'violent learners', 'noise levels' }\end{array}$ & 56 \\
\hline Workload & $\begin{array}{l}\text { 'the amount of administration cause a lot of frustration', 'there is too much administration', 'always busy } \\
\text { with administration', 'the really stressful part is the admin', 'assessments', 'the size of classes', 'too many } \\
\text { classes' } \\
\text { 'there is too much work load', 'work load is a lot', 'workload is often unbearable', 'because there is so much } \\
\text { to do', 'deadlines', 'meetings' }\end{array}$ & 47 \\
\hline Department & $\begin{array}{l}\text { 'lack of support from the education department', 'there is no recognition for hard work', 'don't recognise } \\
\text { educators in decision making', 'district officials have positions of "power" for which they have never } \\
\text { been trained', 'teachers are often bullied by district officials', 'too many rights for children', 'little rights for } \\
\text { teachers', 'district officials are not properly trained for their job' }\end{array}$ & 20 \\
\hline Parents & $\begin{array}{l}\text { 'learners come from homes where they are neglected and not stimulated academically', 'parents don't instil } \\
\text { a sense of responsibility in their kids', 'parental ignorance', 'no interest or participation by parents', 'verbal } \\
\text { abuse by parents', 'unstable homes', 'lack of parent[al] involvement' }\end{array}$ & 11 \\
\hline Remuneration & $\begin{array}{l}\text { 'and we get paid peanuts', 'the department is overworking teachers with little compensation', 'we still do not } \\
\text { get decent salaries' }\end{array}$ & 8 \\
\hline Extramural activities & 'extramural activities', 'no time to teach', 'too many extramural activities' & 7 \\
\hline Resourcing (equipment, logistics, training) & $\begin{array}{l}\text { 'faulty equipment', 'transport for extramural activities', 'learners without textbooks', 'no training for } \\
\text { extramural activities', 'low level of sport skills' }\end{array}$ & 6 \\
\hline Colleagues/staff & $\begin{array}{l}\text { 'substitution for absent educators', 'educator-educator relationship', 'negative staff attitude', 'absent } \\
\text { educators' }\end{array}$ & 4 \\
\hline School management & 'management style', 'dysfunctional schools', 'dealing with classes you don't teach on a regular basis' & 3 \\
\hline Other & 'class environment', 'continuous lowering of standards'(*) [single citation each] & 2 \\
\hline TOTAL RESPONSES & & 164 \\
\hline
\end{tabular}

All the phrases that received two or more citations are summarised in Figure 2. A sizeable number was cited only once and, while this is incorporated in Table 3, it is omitted from Figure 2.

Figure 2 reveals concerns that are experienced by the educators as stressful. Learner indiscipline, high levels of administrative work (which exacerbate existing workload concerns) and the indifferent and negative attitudes of learners were most frequently cited. Considerations such as difficulty experienced with the Department of Education (a perceived lack of support, 'bullying' etc.), poor remuneration, disrespectful conduct by learners towards educators, unsupportive parents and a number of other issues contributed to the educators' experience of stress at work. The number of variables relating to learners and the frequency with which the variables were raised (such as learner discipline and conduct) suggests that the educators experienced great frustration as a direct consequence of learners.

Several of the cited factors revealed similarities or appeared related. Where these seemed to convey similar meaning or intent, they were combined into new categories, which formed the basis for the themes. In this manner, eightcategories (or themes) relating to the causes of stress and burnout were identified, namely a negative learner profile, excessive workload, an unsupportive Department of Education, unsupportive and uninvolved parents, poor remuneration, extramural responsibilities, colleagues and inadequate management at school level. Table 3 provides an overview of these categories, together with frequency counts per category and verbatim excerpts of illustrative narratives provided by the educators.

The learner profile and, in particular, the lack of discipline of the learners, negative learner attitude and disrespectful conduct were indicated as the most prominent contributors to the stress levels of the educators ( $34 \%$ of the responses). This was followed by educator workload ( $28.7 \%$ of the responses), which was characterised by extensive and time-consuming administrative demands. In this regard, the educators referred specifically to the OBE system, which was recently implemented and which placed numerous additional administrative duties on the educators. This source of stress also entailed general administration, meetings, deadlines, assessments and large classes of learners, which was exacerbated when educators were absent from duty. The Department of Education (12\% of the responses) and, specifically, its lack of support for, and recognition of, the educators and the inappropriate use of power by district officials were regularly indicated as contributing factors to educator stress levels. Poor parent involvement in the schooling of their children and their lack of support for their children's education (7\% of the responses) similarly influenced the educators' work experience adversely. The educators mentioned that they had to endure verbal abuse from parents who also expected educators to fulfil the parental role. These four factors accounted for $81.7 \%$ of the educator responses, while learner profile and workload accounted for some $62.7 \%$ of the responses.

Although several other factors were mentioned less frequently, they nonetheless constituted influence and compounded the educators' experience of their work in a manner that contributed to stress and burnout. These factors also included perceived poor remuneration ( $5 \%$ of the responses), too many extramural activities $(4.3 \%$ of the responses) and poor or inadequate educational resources ( $4 \%$ of the responses). The last-mentioned ranged from poor and faulty equipment, to the absence of basic teaching materials (such as textbooks), to the absence of logistical support (transport for extramural activities), to inadequate training and preparation for educator responsibilities. These factors also included colleague commitment $(2.4 \%$ of the responses), with colleagues lacking responsibility, displaying negative attitudes and often being absent from duty, and ineffective school management ( $2 \%$ of the responses).

Included in these categories (the sources of stress) was commentary on the incidence of socially undesirable conduct (such as violence, drug and alcohol abuse, theft at school and a lack of respect for adults). At the same time, technology in the form of the use of cellular phones (and Mix-it) at school and in class provided learners with enhanced yet low-cost access to co-learners and to socially undesirable websites. This impacted 
TABLE 4

MBI-GS scores for the five candidates with the highest test scores

\begin{tabular}{|c|c|c|c|c|}
\hline & \multicolumn{4}{|c|}{ SUBSCALES OF THE MBI ${ }^{\mathrm{a}}$} \\
\hline & EXHAUSTION & PERSONAL EFFICACY & CYNICISM & DEPERSONALISATION \\
\hline \multicolumn{5}{|c|}{ RESPONDENT } \\
\hline A & 30 & 16 & 23 & 24 \\
\hline B & 29 & 6 & 13 & 22 \\
\hline C & 30 & 5 & 27 & 19 \\
\hline D & 26 & 12 & 19 & 25 \\
\hline E & 27 & 17 & 24 & 24 \\
\hline
\end{tabular}

a Minimum and maximum scores for exhaustion, cynicism and depersonalisation are 5 and 30 and, for personal efficacy, 6 and 36 . The syndrome manifests in a pattern of high scores for exhaustion, cynicism and depersonalisation and low scores for personal efficacy.

on the educators' experience of the class environment and their work environment generally.

Table 3, in summary, indicates that learners and workload were the most pronounced sources of stress and, consequently, of potential burnout, followed closely by the lack of perceived support from the Department of Education and parents.

\section{Interview transcription and analysis}

In addition to the written narratives provided by the 59 educators, interviews were also conducted with the five educators who scored highest on the burnout indices of the MBI-GS and whose profiles fitted the typical burnout pattern of high exhaustion, cynicism and depersonalisation and low personal efficacy (Table 4). Barkhuizen and Rothmann (in press) indicated that these scales, when viewed together, suggest a greater probability of burnout. Moreover, consistent with Schaufeli's proposition, the highest-scoring $5 \%$ to $7 \%$ of the participants, after the exhaustion and cynicism scores were integrated, represented the serious cases of burnout (M. Leiter, personal communication, September 26, 2008). These cases are presented in Table 4.

The interviews represented a second but different data-gathering method on the same subject (triangulation). Similar findings (or themes) were obtained from the interviews, which are indicated in Table 5 (where the themes and the number of interviewees who raised them are reported).

The interview results confirmed the educators' frustration with the current schooling system (Table 5). The five educators who participated in the interviews all indicated that the current learner profile and, especially, negative learner attitudes and behaviour were the most important sources of stress and potential burnout. Negative learner behaviour included rude and disruptive behaviour, high noise levels, no work ethic, low motivation and no discipline. Statements that illustrated this were 'learners do not know how to behave themselves in a disciplined way', 'it is very difficult at the moment to instil discipline' and 'we deal with disrespectful, undisciplined learners'. The centrality of this factor was confirmed by the frequency with which the absence of adequate mechanisms to sanction undesirable behaviour was cited. This caused the educators to feel inadequate in dealing with difficult students.

The second major source of stress was work overload. This was evidenced in statements such as the administration we have lately is enormous', 'preparation can take a lot of time', 'they expect a lot more administration from you', 'we need to do an extreme amount of paperwork' and 'preparation takes a lot of time and it makes you feel very demotivated'. Consistent with the data obtained from the written narratives, work overload was again indicated in terms of administration, meetings, changing curricula and the marking of tests and assignments. The educators also again indicated OBE as a primary reason for their work overload; they mentioned that the excessive size of the classes was preventing the effective implementation of OBE. Too much marking, preparation and filling in of forms added
TABLE 5

Probable reasons for burnout from the interview results

\begin{tabular}{ll}
\hline REASON FOR POSSIBLE BURNOUT & $\begin{array}{c}\text { NO. OF INTERVIEWED EDUCATORS } \\
\text { CITING REASON }\end{array}$ \\
\hline LEARNER PROFILE & $\mathbf{5}$ \\
a) Negative learner attitude and behaviour & 4 \\
b) Lack of punishment systems & 2 \\
c) Low primary-level education & 5 \\
WORK OVERLOAD & 3 \\
a) Size of classes & 4 \\
LACK OF DEPARTMENTAL SUPPORT & 1 \\
a) Pressure to get learners to pass & \\
LACK OF PARENTAL SUPPORT & 4 \\
LOW COLLEAGUE COMMITMENT & 3 \\
MULTICULTURAL CONTEXT & 2 \\
a) Language barrier & \\
b) Cultural differences & \\
MANAGEMENT & 2 \\
\hline
\end{tabular}

to the high administration levels. They also found it difficult to accommodate the number of students in each class. The educators, in addition, regularly had to attend time-consuming meetings, which further increased their workload.

A lack of support from the Department of Education and a lack of parental support were also indicated as prominent factors affecting the educators' stress levels and possible burnout. A statement such as 'another thing that upset me is the attitude of the department' was repeatedly mentioned (with slight modifications) and was illustrative of how the Department of Education was being experienced. Parents, in turn, were working long hours, were unable to assist learners with homework and were generally perceived as unsupportive. Illustrative statements included 'parents give their children over to television', 'you need to take over the role of parents', 'when parents get phoned about their child's bad behaviour they place the blame on the teacher', 'there is just no parent support', 'half the problem lies with the parents or the home environment' and 'educators have to take over the role of the parents'.

Three educators raised the issue of noncommittal colleagues as contributing to their stress levels and mentioned incompetent colleagues, absenteeism and low commitment from colleagues. These educators did not want to use their free periods standing in for educators who were absent on a regular basis, since free periods were needed to attend to the excessive loads of administrative work expected of them. Illustrative statements included 'educators are not as committed to their job as they 
were a number of years ago' and 'there are many absenteeisms, and it results in negative feelings from other educators'.

A factor that did not emerge in the written narratives related to the strains brought about by a multicultural context. In this regard, two educators commented on the challenges of cultural differences and language barriers. The cultural differences in schools, particularly when they differed from the culture of the educators, appeared to contribute to a loss of control in the classroom. The educators mentioned that they found it difficult to discipline and assume control of a class while attempting not to offend anyone's culture. Some forms of behaviour could for example, be acceptable in one culture but not in another ('it is not easy to accommodate many cultures' and 'the cultural differences make it very difficult'). Language barriers were a contributing factor to an adverse work experience, with the educators required to teach in a language other than their home language. The educators noted that it was stressful to teach in a second language due to the fact that teaching came naturally in their home language. Learners also found it difficult to comprehend fully when taught in their second language, more so when a fair number of learners were not fluent in English.

In addition to these factors, the educators noted that poor (low) remuneration levels impacted on their motivation, especially as financial difficulties at home further added to the pressure that they were experiencing. The poor standard and level of education in primary schools again surfaced, with learners at secondary schools presenting with poor reading and study skills. The interviewed (secondary-school) educators felt that it was not their responsibility to teach learners to read.

As outlined, the factors perceived by the educators to impact on and contribute to their levels of stress and potential burnout closely paralleled those observed from the general narratives obtained from all the educators. The exception was that the interviewed educators, who represented a small proportion $(8.4 \%)$ of the educators involved in the study, demonstrated the burnout pattern and had higher scores than their colleagues. This consistency builds confidence in the observations and supports the relative importance of the identified stressors.

\section{DISCUSSION}

The aim of this study was to explore the origins, that is, the probable reasons for burnout among secondary educators. To this end, a convenience sample comprising all the educators at three secondary schools was engaged in the research. The first objective was to establish the incidence of burnout among the educators at these schools, which would then provide the basis for exploring the reasons for or causes of the observed cases of educator burnout.

\section{The incidence and extent of experienced burnout}

On average, the majority of the educators did not test high for burnout and only five educators demonstrated the very common burnout pattern of high scores for exhaustion, cynicism and depersonalisation and low scores for personal efficacy. Although technically not considered burnt out (according to the traditional assessment of burnout), these educators revealed behavioural patterns that were consistent with and in the direction of burnout as measured by the MBI. If, for example, the 'internal burnout' and 'external burnout' types (Johnson, 1991) or, more likely, the 'high burnout' and 'low burnout' types identified by Loo (2004) are used as categorisation frames, it may well be concluded that these individuals were experiencing early or intermediate stages or forms of burnout. Moreover, if the phase model of burnout by Golembiewski and Munzenrider (1988) is used in a similar manner to that employed by Mirvis et al. (1999) in their study of burnout among leaders in the Department of Veterans Affairs, it could be concluded that these educators were experiencing an intermediate to advanced stage of burnout. Golembiewski, Munzenrider and Stevenson (1985) argued that institutional burnout levels should ideally not be more than 5\% and that a $10 \%$ incidence of the phenomenon is tolerable.

From this perspective, the low incidence of burnout noted in this study was heartening, as the five educators bordering on burnout represented only $8.4 \%$ of the engaged sample. Note also that this study, in its approach to the identification of the sources of potential burnout, did not ask the educators to list areas of stress or concern. Rather, the 59 respondents were asked in a non-directive and neutral manner to provide a short description of how they experienced their work. In a similar manner, the five interview respondents were requested to indicate how they felt about and experienced their jobs. The salience and prevalence of the sources of discontent (Figure 2 and Tables 3 and 4) were suggestive of the stressful nature of the educators' work experience. Note in this regard that stress is considered to be the principal cause of work-related illness in the UK education sector (Clarkson \& Hodgkinson, 2007). Clarkson and Hodgkinson argued that the incidence of self-reported stress and the related conditions of depression and anxiety in the education sector are considered to be among the highest when compared to other industries (Clarkson \& Hodgkinson, 2007, p. 686).

With stress being positively related to burnout (Gill et al., 2006; Jamal \& Baba, 2000; Kittel \& Leynen, 2003; McManus et al., 2002), this implies that each of the remaining 54 respondents in the sample, apart from those educators in this study that were substantially further along the road to burnout, may, at some stage, suffer burnout. Conservatively and subject to the findings of this study being replicated in more expansive and representative studies, the $8.4 \%$ of the educators in this study could mean that approximately 32474 of the 386600 South African educators ${ }^{2}$ could be close to burnout or could be experiencing burnout. The remaining educators could all be likely to experience stress to a lesser extent.

Regardless of how the situation is viewed, the results of this study suggest that educator stress and burnout are cause for concern. This line of reasoning is consistent with the underlying concern evidenced in the scope and frequency with which the subject of burnout among educators is garnering attention across the globe (Burke \& Greenglass, 1996; Cherniss, 1980; Hughes, 2001; Kittel \& Leynen, 2003). It is undoubtedly an increasingly probable occupational hazard for educators and, if the situation is not addressed, consistent with research on the phase model of burnout, educators are bound to progress to higher levels of burnout, which translates into a deterioration of personal and work well-being (Maslach et al., 2001, p. 405). These views underscore the importance of attending to burnout and, specifically, to the origins or root causes that give rise to its onset.

\section{Probable causes of stress and potential burnout}

Turning to the results obtained from the 59 educators (Figure 2 and Table 3), several prominent themes (probable causes) for the largely negative work experience are noted. These correspond broadly with those obtained from the five interviewed educators, raising similar reasons for their stress levels. This demonstrated a consistent response pattern across all the interviews.

This study revealed that the two greatest contributing factors to the high levels of stress of the interviewed educators (bordering on burnout proper) were the behaviour and attitudes of learners (the learner profile) and the experienced workload of the educators. These observations were consistent with research in international settings, which also found that pupil attitude and behaviour and workload were leading sources of stress among

2.Jackson and Rothmann (2005a) indicated that approximately 375000 teachers were employed at the time of their research in 2005 . In 2006, the number of educators in the en at the tim in the employ of the South Afican government numbered 386505 (Department of Education, 2006). This figure, rounded up to 386600 , is still reported in Education in South Africa (http://www.southafrica.info/about/education/education.htm, accessed on 14 February 2009). 
educators (Antoniou et al., 2006; Cooper \& Kelly, 1993; Griva \& Joekes, 2003; Kittel \& Leynen, 2003).

The prominent position of learner profile and, in particular, learner attitude and conduct (such as indiscipline and a lack of respect) and of the challenges of dealing with difficult learners is consistent with research, which has found this to be a major predictor of burnout among educators (Antoniou et al., 2006; Kittel \& Leynen, 2003; Taris et al., 2004). Taris et al. (2004) observed that inequity in the relationship between teachers and students has the strongest effect on burnout and argued that improvement in this relationship improves educator well-being but does not necessarily improve educator turnover rates.

Workload emerged as the second major stressor for the educators. The educators indicated that the size of classes (number of students) and OBE were at the root of the increasing workload and were pronounced stress factors. This finding was consistent with earlier research by Pretorius (1994), who found that the number of students and experienced role conflict were significant predictors of emotional exhaustion among South African educators, while the number of students and role ambiguity significantly predicted depersonalisation. Role conflict and role ambiguity did not surface in this study to the same extent as they did in the Pretorius study, since, at the time of the Pretorius study, South Africa's transition to a new political dispensation induced widespread uncertainty around anticipated changes in existing educational policy and practice. In this study, it was the implementation of OBE that was frequently mentioned as a reason for burnout. This finding is in line with research that suggests that change in the educational sector generally, including changing curricula, increases the stress levels of educators (Clarkson \& Hodgkinson, 2007; Forlin, 2001; McCormick et al., 2006; Travers \& Cooper, 1996). More than a decade later, these uncertainties have become realities, which entail large numbers of previously disadvantaged students gaining access to education together with an inadequate resourcing base and the adoption of the OBE philosophy to education. Viewed in conjunction with the third and fourth major sources of stress and burnout - the perceived lack of support from the Department of Education (often the district office) and the absence of a positive parental role - it seems plausible that coping with these systemic and 'extraschool' difficulties could be perceived to be a greater personal challenge than the possible role conflict and role ambiguity that could remain. By contrast, role and work overload, as observed in this study, did not surface as a material source of burnout as it did in a study that involved expatriates (Bhanugopan \& Fish, 2006). This suggests the importance of context; in this study, an unsupportive context, as evidenced in the lack of departmental and parental support, appeared to be a prominent source of stress. Apart from the cited factors, the fact that many educators have left the profession further complicates remaining educators' work experience. These considerations could, in part, contribute to the prominence of class size and administrative duties in educators' experience of excessive workload.

Larger classes or 'overcrowded classrooms' (cf. Antoniou et al., 2006, p. 685), however, do not appear to be uniquely South African. Sari (2004), in a study of Turkish educators, also reported that the size of classes (number of students) and educational policies and procedures were material indicators of burnout and recommended that, for example, excessive administrative tasks be addressed by Turkish educational policy-makers. Class sizes could therefore be an indication of the development status of developing countries as opposed to developed countries. Work overload may also, however, be a consequence of a changing world of work, as Angerer (2003, p. 102) stated: 'In today's challenging work environment, teachers have larger classes, doctors have more patients, and bank tellers are handling more transactions'.

Growth in the size of classes unavoidably impacts on discipline and learner conduct, as educators invariably find it difficult to exercise control over such classes. The 'control' theme is an important one and it has been raised regularly by researchers (Angerer, 2003). In this regard, it is important that educators experience a measure of control in key aspects of their work (such as in the classroom), as low levels of control could predispose them to exhaustion, cynicism and ineffectiveness (Angerer, 2003). In this study, the educators indicated their frustration with continuously reducing levels of control, especially control over discipline in their classrooms. They argued that there is hardly any measure that is effective in dealing with unacceptable behaviour in classrooms (Table 3). This situation of perceived educator disempowerment commenced with changes in educational legislation and policy post-1994, which related to, among other things, means of discipline and punishment, elaborated roles and greater influence of students in some school-management domains (Van Tonder, 1997).

Less commonly observed in the literature is the observation of poor support from the Department of Education (often district offices) and parents. As indicated earlier, both these stressors suggest an unhelpful context. In this sense, the results suggest a marked role for contextual consideration, in addition to consideration of the more common work and personal stressors. The role of government is infrequently commented on and only occasionally surfaces in the literature (Antoniou et al., 2006; Sari, 2004), while parental support is perhaps acknowledged more frequently as a source of stress. Under such circumstances, educators feel (and have stated this in written narratives and interviews) that their contribution is not recognised. The significance of such a lack of appreciation becomes clear when it is noted that this variable was the only job stressor that related positively to all burnout dimensions for both white and blue-collar employees (Toppinen-Tanner et al., 2002). Accordingly, when educators feel under-appreciated or are not recognised for their contributions (an attribution when departmental and parental support is lacking), their experienced emotional exhaustion and cynicism intensifies and their sense of professional efficacy declines.

Poor remuneration levels are a known stressor, which was similarly cited by the educators in this study. As indicated by Leiter and Maslach (2001), perceived unfair treatment, whether financially, promotionally or in any other way, invariably impacts on individuals' relationships with their work. This, in turn, decreases engagement with work and moves educators closer to burnout, a view that is consistent with earlier findings of Pines (1993), who similarly reported unfairness of reward as a cause of burnout. Associated with reward is the availability of school resources, which directly affects the level of educator empowerment. Although not among the four most frequently cited stressors, there is no tangible evidence to argue that stressors singularly impact on burnout. A more plausible hypothesis would be that multiple interdependent sources of stress interact in as yet unknown ways to contribute to educator burnout. From this perspective, the resourcing of schools (or, rather, the lack thereof) is an important source of educator burnout, as demonstrated by several researchers (Mirvis et al., 1999; Oshagbemi, 2000; Sari, 2002).

In addition, the educators interviewed in this study indicated that (poor) commitment from colleagues meaningfully impacted on their stress levels. This observation was in line with observations by Griva and Joekes (2003) and Sari (2000), who indicated that poor relationships with colleagues and superiors were a pronounced source of stress for educators.

This study, however, revealed a number of reasons for burnout that are infrequently cited. These included low primary-education levels, extramural activities, drug and alcohol abuse, language barriers, cultural differences and a lack of effective disciplinary systems. These themes appeared to reflect the consequences of a society and education system in transition that posed substantial challenges to educational managers. 
In summary: Firstly, even though the majority of educators still demonstrated a commitment towards teaching, they conveyed frustration with the current school environment. They felt underpaid, unsupported and left with little or no means to control and regulate undisciplined learners. Secondly, the sources of educator stress and burnout identified in this study were consistent with the findings of a considerable body of international research and very similar to those observed for Greek and Turkish educators (Antoniou et al., 2006; Sari, 2004). It is consequently concluded that the causes of burnout among educators appear to be universal, especially the prominence of learners (discipline and conduct) and educator workload. The relative emphasis accorded to specific sources of educator stress could, however, vary from country to country. In this study, the third and fourth most prominent stressors (the Department of Education and parental support) appeared to be more salient than they might be in the majority of international studies, while a few stressors appeared to be unique to the South African setting.

The identified stressors lend credence to the emergent perspective of burnout as a systemic phenomenon, with the majority of the cited stressors residing in or originating from the institutional and systemic setting within which South African secondary schools are located and operate. This is consistent with other burnout research, which has found that situational and organisational factors perform a more prominent role in burnout compared to individual factors (Maslach, 2001, p. 610). While this does not negate the role of individual factors in the aetiology and development of burnout, these findings have important implications for educational and institutional management.

\section{Implications and recommendations}

Burnout undoubtedly has adverse personal and institutional consequences (Cordes \& Dougherty, 1993; Maslach et al., 2001; Mirvis et al., 1999). In view of the fact that burnout can be prevented and its undesirable effects reduced (Golembiewsk et al., 1987), it follows that scholars will call for organisations to assess the psychological status of their leaders (Burke \& Greenglass, 1991; Burke, Shearer \& Desca, 1984). There is an equal, if not more pressing, need, however, to assess the prevalence and incidence of stress and burnout among the South African educator corps on a regular basis.

This study revealed that the phenomenon of burnout had serious negative consequences for the educators, as evidenced in their accounts of their work experiences. A common behavioural outcome of such situations, if left unattended, is that educators leave the profession or changejobs (Hughes, 2001; Lee \& Ashforth 1990). It is debatable, however, which is the lesser evil: losing educators or retaining burnt-out educators who involuntarily remain in their positions. Hughes (2001, p. 289) argued that many educators accept the consequences of burnout and remain in their positions (for a number of reasons). This has significant detrimental consequences not only for these educators who, in all likelihood, will develop a more severe and intense form of burnout (Mirvis et al. 1999) but also for the organisations, where the phenomenon of burnout adversely affects the student learning experience (Stevenson \& Harper, 2006) and ultimately impacts on the academic achievement of the learners (Blandford, 1999). In the educational sector and, specifically, in primary and secondary education, the role of individual educators is significant beyond description and the impact of educators on young learners, who probably spend more time during their childhood with their educators than with their parents, must be a critical consideration. In fact, several studies have indicated that the social, affective and cognitive development of learners in special schools (and consequently also in ordinary schools) is impacted directly by teachers who are burnt out (Sari, 2004) It is for these reasons that the phenomenon and consequences of burnout require further research. This phenomenon and its adverse effects should be debated among educators and accorded an appropriately high priority on the national agenda for educational management. A thorough understanding of the causes of burnout is necessary if educational effectiveness and efficiency are to be secured, the loss of good educators is to be curbed and the learning experience of learners is to be maximised

The findings of the current study suggested that administrators and the leadership in schools and in the Department of Education should be mindful of educators' stress levels. Maslach and Leiter (1999) argued that the significance of burnout does not reside in viewing the phenomenon as an end state in itself but rather in its role as a mediator of other important outcomes. Some of these, research has informed us, include the quality of the learning experience and the value that learners derive from engaging the education system. The evidence surfaced by this study, viewed from within this framework (Maslach \& Leiter, 1999), suggested that an appropriate philosophy of improving the quality of learners' experience and, consequently, of learning, should be directed at reducing the prominent sources of job stress and burnout in educators' work environment, as these facilitate (mediate) undesirable outcomes. As Um and Harrison (1998) suggested, there is little value in focusing on the development of coping skills when the majority of the stressors are institutionally entrenched. In their study, the primary stressors that contributed to burnout and job dissatisfaction were institutional in nature and included role conflict and contradictory implicit and explicit rules and regulations. Individual coping had little effect on experienced burnout in this study. It follows that, in such circumstances, an effective intervention strategy would be one that was directed at changing the most prominent undesirable features of the work setting and work environment, supplemented with interventions to enhance the coping skills of educators. Of interest is that Oktay (1992), while performing regression analyses, found that support groups were the only significant factor among various other forms of support that actually affected emotional exhaustion negatively. This suggests a potentially productive avenue for intervention but, we would argue, only if systemic sources of stress and burnout are addressed meaningfully.

Aggressive intervention in the burnout process is needed if the negative impact of burnout on both the teacher and the educational process is to be prevented (Hughes, 2001, p. 297). For intervention to be effective, however, it should be systemic (Taris et al., 2004) and should address stressors originating in the work and personal environments of educators (Maslach et al., 2001), such as work overload, a lack of control, insufficient reward, a breakdown in the work (educator) community, the absence of fairness and conflicting values (Angerer, 2003). At the same time, effective intervention cannot rely on generic approaches imported from other settings but should be context and situation-specific (McCarty, Zhao \& Garland, 2007), the latter being a prominent source of stressors in this study.

Many companies have pursued these concerns in an attempt to establish more employee-friendly work environments. A recent study by Garman, Corrigan and Morris (2002), for example, recorded significant relationships between the emotional exhaustion levels of hospital staff and customer (patient) satisfaction. These findings suggested that the inverse of burnout, i.e. enthusiastic, engaged or committed, loyal and effective employees, positively influences the customer or client experience. From this perspective, it could be concluded that even an incremental improvement in the indicated intervention areas (for the entire educational system) would translate into a dramatic improvement in the learning experience of learners.

\section{Avenues for future research}

This study suggests several areas for future research. Such research should focus on establishing the scope and frequency of experienced burnout in the educational sector at large. It should 
also engage larger and more representative samples of secondary schools across the country and should reveal which regional areas or sub-populations (if any) are more vulnerable and more at risk. It should furthermore identify common yet critical areas of management intervention in the schooling system, which could help to define a national strategy for combating stress, burnout and related illnesses among educators. Such a strategy should identify specific sources of stress and should target these to optimise educator effectiveness and, consequently, to ensure an improved learning experience for students. Building on this study, rigorous and more positively inclined studies that aim to establish the relative prominence and influence of the different sources of stress and burnout should be pursued. Such studies should aim to establish, more precisely, what the correlates and consequences of the identified stressors are and how these influence the development of burnout among educators. Finally, replication and cross-cultural studies using similar measures of burnout should be undertaken to establish a valid and reliable knowledge platform for this country.

\section{Limitations of the study}

As with all studies, this study is also characterised by constraints, which suggest caution in the interpretation of the results. The first limitation relates to the three schools that participated. They were not selected randomly or representatively but were the result of a convenience sample. All three were also primarily located in an urban setting. For these reasons, the results, while valid for these schools, cannot be extended to the broader educational setting.

The second limitation relates to the fact that it was not possible to establish how the educators compared with their international counterparts in terms of burnout levels (the first part of the study). Even though the MBI is the most widely used measure of burnout, variation in the final composition of the MBI scales (and items) that are included or omitted do occur. This prevents a meaningful comparison of results across studies. In this study, this was also the case and, although similar scale selection to that used by Jackson and Rothmann (2005a) was followed, the two items (13 and 18$)^{3}$ that they omitted in their burnout model for South African educators were not omitted in this study, which, unfortunately, renders the data sets incomparable.

The participation of the educators in this study was secured through the school managers and, while the educators appeared to participate willingly, their degree of rapport and comfort with the study was difficult to gauge. Some of the respondents were, in fact, notably reluctant to communicate openly. The third limitation of this study is that it did not consciously consider the potential impact of diversity or the timing of the study (measurement specifically). Although burnout is an enduring and long-term phenomenon, its presence could be felt or observed more prominently at certain times in the school calendar, such as before examinations. These considerations suggest that future research should consciously incorporate such variables.

\section{Conclusion}

Although this study does not purport to be representative, the very nature of qualitative approaches and methodologies is such that, if these are appropriately executed, they do generate valid perspectives, which allow for some transferability to similar situations. This study's contribution resides primarily in this area, as it provides a valid account of sources of stress and burnout among secondary educators, which aligns with that of international studies. This provides a definite point of departure for thinking about managing burnout and establishes a useful platform from which to pursue the incidence of burnout in the South African educational setting further as well as the

3.Item 13 stated 'I just want to do my job and not be bothered' and Item 18 stated 'I've become more callous towards people since I took this job'. relative prominence of specific factors that contribute to the onset of burnout among educators. The study also sensitises the education community to the very real problems that educators (certainly in the sampled schools) experience and that cause discomfort and illness. In this sense, it suggests the need for intervention.

Finally,

'...it is not only up to teachers and head teachers to figure out and work for what they hope for: it is up to parents, students, policy makers, labour and business leaders, politicians and the media as well. Rebuilding and redefining education and its relationship to the world "out there" is a job for citizens and society as a whole'.

(Hargreaves \& Fullen, 1998, p. 127)

\section{REFERENCES}

Ahola, K., Honkonen, T., Isometsä, E., Kalimo, R., Nykyri, E., Aromaa, A., et al. (2005). The relationship between jobrelated burnout and depressive disorders - Results from the Finnish health 2000 study. Journal of Affective Disorders, $88,55-62$.

Angerer, J.M. (2003). Job burnout. Journal of Employment Counselling, 40(3), 98-107.

Antoniou, A.S., Polychroni, F., \& Vlachakis, A.N. (2006). Gender and age differences in occupational stress and professional burnout between primary and high school teachers in Greece. Journal of Managerial Psychology, 21(7), 682-690.

Bakker, A.B., Schaufeli, W.B., Demerouti, E., Janssen, P.M., Van der Hulst, R., \& Brouwer, J. (2000). Using equity theory to examine the difference between burnout and depression. Anxiety, Stress, and Coping, 13, 247-268.

Bakker, A.B., Van der Zee, K.I., Lewig, K.A., \& Dollard, M.F. (2006). The relationship between the big five personality factors and burnout: A study among volunteer counsellors. Journal of Social Psychology, 146(1), 31-50.

Barkhuizen, N., \& Rothmann, S. (in press). Burnout of academic staff in South African higher education institutions. South African Journal of Higher Education.

Barkhuizen, N., Rothmann, S., \& Tytherleigh, M.Y. (in press). A model of work-related well-being of academic staff in a South African higher education institution. South African Journal of Higher Education.

Barnett, R.C., Brennan, R.T., \& Gareis, K.C. (1999). A closer look at the measurement of burnout. Journal of Applied Biobehavioral Research, 4(2), 65-78.

Bhanugopan, R., \& Fish, A. (2006). An empirical investigation of job burnout among expatriates. Personnel Review, 35(4), 449-468.

Blandford, S. (1999). Managing discipline in schools. London: Routledge.

Botha, P.A. (2006, 27 June-01 July). Emotional wellness behaviour risks associated with stress, burnout, anxiety, and depression. Paper presented at the 2006 international conference of the Global Business and Technology Association, Moscow.

Brock, B.L., \& Grady, M.L. (2000). Rekindling the flame: Principals combating teacher burnout. Thousand Oaks: Corwin Press.

Burke, R.J., \& Greenglass, E.R. (1991). A longitudinal study of progressive phases of psychological burnout. Journal of Health and Human Resources Administration, 13(4), 390-408.

Burke, R.J., \& Greenglass, E.R. (1996). Work stress, social support, psychological burnout and emotional and physical well-being among teachers. Psychology, Health and Medicine, 1, 193-205.

Burke, R.J., \& Greenglass, E.R. (2001). Hospital restructuring, work-family conflict and psychological burnout among nursing staff. Psychological Health, 22, 123-132.

Burke, R.J., Shearer, J., \& Desca, G. (1984). Burnout among men and women in police work. Journal of Health and Human Resources Administration, 7(2), 162-188.

Calvert, G.M., Flynn, R., Fraser, P., \& Long, J. (1991, April). Volunteers' motivation and the Terrence Higgins Trust. Presentation given at the British Psychological Society Conference, London. 
Cherniss, C. (1980). Staff burnout: Job stress in the human services. Beverley Hills: Sage Publications.

Clarkson, G.P., \&Hodgkinson, G.P. (2007). What can occupational stress diaries achieve that questionnaires can't? Personnel Review, 36(5), 684-700.

Cohen, J. (1988). Statistical power analysis for the behavioral sciences (rev. edn.). Orlando: Academic Press.

Cooper, C.L., \& Kelly, M. (1993). Occupational stress in head teachers: A national UK study. British Journal of Educational Psychology, 63, 130-143.

Cordes, C.L., \& Dougherty, T.W. (1993). A review and integration of research on job burnout. Academy of Management Review, 18(4), 621-656.

Creswell, J.W. (2003). Research design: Qualitative, quantitative, and mixed methods approaches. (2nd edn.). Thousand Oaks: Sage Publications.

Denzin, N.K., \& Lincoln, Y.S. (Eds.). (1994). Handbook of qualitative research (2nd edn.), (n.p.). Thousand Oaks: Sage Publications.

Denzin, N.K., \& Lincoln, Y.S. (2005). Introduction: The discipline and practice of qualitative research. In N.K. Denzin \& Y.S Lincoln (Eds.), Handbook of qualitative research (3rd edn.), (n.p.). Thousand Oaks: Sage Publications.

Department of Education. (2006). 2006 school realities. Retrieved n.d., from http://www.education.gov.za.

Dinham, S., \& Scott, C. (2000). Moving into third: Outer domain of teacher satisfaction. Journal of Educational Administration, 38(4), 379-396.

Esterberg, K.G. (2002). Qualitative methods in social research. Boston: McGraw Hill.

Forlin, C. (2001). Inclusion: Identifying potential stressors for regular class teachers. Educational Research, 43, 235-245.

Freudenberger, H.J. (1974). Staff burnout. Journal of Social Issues, 30, 159-165.

Freudenberger, H.J. (1975). The staff burnout syndrome in alternative institutions. Psychotherapy Theory Research Practice, 12, 72-83.

Friedman, I.A. (1991). High- and low-burnout schools: School culture aspects of teacher burnout. Journal of Educational Research, 84, 325-333.

Garman, A.N., Corrigan, P.W., \& Morris, S.B. (2002). Staff burnout and patient satisfaction: Evidence of relationships at the care unit level. Journal of Occupational Health Psychology, 7, 235-241.

Gill, A.S., Flaschner, B., \& Shachar, M. (2006). Mitigating stress and burnout by implementing transformational leadership. International Journal of Contemporary Hospitality Management, 18(6), 469-481.

Golden, J., Piedmont, R.L., Ciarrocchi, J.W., \& Rodgerson, T. (2004). Spirituality and burnout: An incremental validity study. Journal of Psychology and Theology, 32(2), 115-125.

Golembiewski, R.T., \& Boss, R.W. (1991). Shelving levels of burnout for individuals in organizations: A note on the stability of phases. Journal of Health and Human Resources Administration, 13(4), 409-423.

Golembiewski, R.T., Hilles, R., \& Daly, R. (1987). Some effects of multiple OD interventions on burnout and work site features. Journal of Applied Behavioral Science, 23(3), 295-313.

Golembiewski, R.T., \& Munzenrider, R.F. (1988). Phases of burnout: Developments in concepts and applications. New York: Praeger.

Golembiewski, R.T., Munzenrider, R.F., \& Stevenson, J. (1985). Stress in organizations. New York: Praeger

Griva, K., \& Joekes, K. (2003). UK teachers under stress: Can we predict wellness on the basis of characteristics of the teaching job? Psychology and Health, 18(4), 457-471.

Hargreaves, A., \& Fullan, M. (1998). What's for fighting out there? Ontario: Teachers College Press.

Hoops, B.K. (1999). The truth about burnout: How organisations cause personal stress and what to do about it. Psychiatric Rehabilitation Journal, 23(2), 194.

Houkes, I.P., De Jonge, J., \& Bakker, A.B. (2003). Specific determinants of intrinsic work motivation, emotional exhaustion, and turnover intention: A multisample longitudinal study. Journal of Occupational \& Organisational Psychology, 76, 427.

Hughes, R.E. (2001). Deciding to leave but staying: Teacher burnout, precursors and turnover. The International Journal of Human Resource Management, 12(2), 288-298.

Jackson, L.T.B., \& Rothmann, S. (2005a). An adapted model of burnout for educators in South Africa. South African Journal of Education, 25, 100-108.

Jackson, L.T.B., \& Rothmann, S. (2005b). Work-related well being of educators in a district of the North West Province. Perspectives in Education, 23(3), 107-122.

Jamal, M., \& Baba, V.V. (2000). Job stress and burnout among Canadian managers and nurses: An empirical examination. Canadian Journal of Public Health, 91(6), 454-459.

Johnson, L.B. (1991). Job strain among police officers: Gender comparisons. Police Studies, 14, 12-16.

Kittel, F., \& Leynen, F. (2003). A study of work stressors and wellness/health outcomes among Belgian school teachers. Psychology and Health, 18(4), 501-510.

Koeske, G.F., \& Koeske, R.D. (1989). Construct validity of the Maslach Burnout Inventory: A critical review and reconceptualisation. The Journal of Applied Behavioural Science, 25(2), 131-144.

Lee, R.T., \& Ashforth, B.E. (1990). On the meaning of Maslach's three dimensions of burnout. Journal of Applied Psychology, 75, 743-747.

Leiter, P.M., \& Maslach, C. (2001). Burnout and quality in a sped-up world. The Journal for Quality and Participation, 24(2), $48-51$.

Levinson, H. (1996). When executives burn out. Harvard Business Review, 74, 152-157.

Loo, R. (2004). A typology of burnout types among police managers. Policing: An International Journal of Police Strategies E Management, 27(2), 156-165.

Maslach, C. (1982). Burnout: A social-psychological analysis. In J.W. Jones (Ed.), The burnout syndrome, (n.p.). Park Ridge: London House.

Maslach, C. (2001). What have we learned about burnout and health? Psychology and Health, 16, 607-611.

Maslach, C., \& Jackson, S.E. (1981). The measurement of experienced burnout. Journal of Occupational and Behavioural Science, 2, 99-113.

Maslach, C., Jackson, S.E., \& Leiter, M.P. (1996). Maslach Burnout Inventory Manual. (3rd edn.). Palo Alto: Consulting Psychologists Press.

Maslach, C., \& Leiter, M.P. (1997). The truth about burnout: How organisations cause personal stress and what to do about it. San Francisco: Jossey-Bass.

Maslach, C., \& Leiter, M.P. (1999). Burnout and engagement in the workplace: A contextual analysis. In T. Urdan (Ed.), Advances in motivation and achievement, vol. 11 (n.p.). Stamford: JAI Press.

Maslach, C., Schaufeli, W.B., \& Leiter, M.P. (2001). Job burnout. Annual Review of Psychology, 52, 397-422.

McCarty, W.P., Zhao, J.S., \& Garland, B.E. (2007). Occupational stress and burnout between male and female police officers: Are there any gender differences? Policing: An International Journal of Police Strategies E Management, 30(4), 672-691.

McCormick, J., Ayres, P.L., \& Beechey, B. (2006). Teaching self-efficacy, stress and coping in a major curriculum reform: Applying theory to context. Journal of Educational Administration, 44(1), 53-70.

Messmer, M. (2004). Are you burning out your best employee? Strategic Finance, 85(11), 12.

Mirvis, D.M., Graney, M.J., \& Kilpatrick, D.P.A. (1999). Trends in burnout and related measures of organizational stress among leaders of Department of Veterans Affairs medical centres. Journal of Healthcare Management, 44(5), 353-366.

Montgomery, A.J., Panagopolou, E., De Wildt, M., \& Meenks, E. (2006). Work-family interference, emotional labor and burnout. Journal of Managerial Psychology, 21(1), 36-51. 
Moore, J.E. (2000). One road to turnover: An examination of work exhaustion in technology professionals. MIS Quarterly, 24(1), 141-168.

Newman, W.L. (2000). Social research methods: Qualitative and quantitative approaches. Needham Heights: Allyn and Bacon.

Oktay, J.S. (1992). Burnout in hospital social workers who work with AIDS patients. Social Work, 37, 432-439.

Onwuegbuzie, A.J., \& Teddlie, C. (2003). A framework for analyzing data in mixed methods research. In A. Tashakkori \& C. Teddlie (Eds.), Handbook of mixed methods in social and behavioral research, (n.p.). Thousand Oaks: Sage Publications.

Oshagbemi, T. (2000). How satisfied are academics with their primary tasks of teaching research and administration and management? International Journal of Sustainable Higher Education, 1(2), 124-136.

Pines, A. (1993). Burnout: An existential perspective. In W.B. Schaufeli, D. Maslach \& T. Marek (Eds.), Professional burnout: Recent developments in theory and research (n.p.). Washington, DC: Taylor \& Francis.

Pines, A., Aronson, E., \& Kafry, D. (1981). Burnout: From tedium to personal growth. New York: Free Press.

Pomaki, G., \& Anagnostopoulou, T. (2003). A test and extension of the demand/control/social support model: Prediction of wellness/health outcomes in Greek teachers. Psychology and Health, 18(4), 537-550.

Pretorius, T.B. (1994). Using the Maslach Burnout Inventory to assess educator's burnout at a university in South Africa. Psychological Reports, 75(2), 771-777.

Ratliff, N. (1988). Stress and burnout in the helping professions. Social Casework, 69(1), 147-154.

Richardsen, A.M., \& Martinussen, M. (2004). The Maslach Burnout Inventory: Factorial validity and consistency across occupational groups in Norway. Journal of Occupational and Organizational Psychology, 77, 377-384.

Rocco, S.T., Bliss, L.A., Gallagher, S., \& Perez-Prado, A. (2003). Taking the next step: Mixed methods research in organisational systems. Technology, Learning, and Performance Journal, 21(1), 19-29.

Rothmann, S. (2003). Burnout and engagement: A South African perspective. South African Journal of Industrial Psychology, 29(4), 16-25.

Sandström, A., Rhodin, I.N., Lundberg, M., Olsson, T., \& Nyberg, L. (2005). Impaired cognitive performance in patients with chronic burnout syndrome. Biological Psychology, 69, 271279.

Sari, H. (2000). An analysis of the policies and provisions of children with SEN in England and Turkey. Doctoral thesis. Oxford: Oxford Brookes University.

Sari, H. (2002). Strategies for teaching children with special educational needs. Ankara: Regema Yayinlari.

Sari, H. (2004). An analysis of burnout and job satisfaction among Turkish special school head teachers and teachers, and the factors effecting their burnout and job satisfaction. Educational Studies, 30(3), 291-306.

Schaufeli, W.B., \& Buunk, B.P. (2005). Burnout: An overview of 25 years of research and theorising. In M.J. Schabracq, C.L. Cooper \& J.A.M. Winnubst (Eds.), Handbook of work and health psychology, (n.p.). Chichester: John Wiley and Sons.

Schaufeli, W.B., \& Enzmann, D. (1998). The burnout companion to study and practice: A critical analysis. Philadelphia: Taylor \& Francis.
Schaufeli, W.B., Leiter, M.P., \& Kalimo, R. (1995, September). The general burnout inventory: A self-report questionnaire to assess burnout at the workplace. Paper presented at Work, Stress and Health '95: Creating Healthier Workplaces, Washington, DC.

Schaufeli, W.B., Leiter, M.P., Maslach, C., \& Jackson, S.E. (1996). Maslach Burnout Inventory - General Survey. In C. Maslach, S.E. Jackson \& M.P. Leiter (Eds.), The Maslach Burnout Inventory: Test Manual (3rd edn.), (n.p.). Palo Alto: Consulting Psychologists Press.

Stevenson, A., \& Harper, S. (2006). Workplace stress and the student learning experience. Quality Assurance in Education, 14(2), 167-178.

Storm, K., \& Rothmann, S. (2003). A psychometric analysis of the Maslach Burnout Inventory - General Survey in the South African Police Service. SA Journal of Psychology, 33, 219-226.

Tang, C.S., Au, W., Schwarzer, R., \& Schmitz, G. (2001). Mental health outcomes of job stress among Chinese teachers: Role stress resource factors and burnout. Journal of Organizational Behavior, 22(8), 887-901.

Taris, T.W., Van Horn, J.E., Schaufeli, W.B., \& Schreurs, J.G. (2004). Inequity, burnout, and psychological withdrawal among teachers: A dynamic exchange model. Anxiety, Stress and Coping, 17(1), 103-122.

Tashakkori, A., \& Teddlie, C. (1998). Mixed methodology: Combining qualitative and quantitative approaches. Applied social research methods series, Vol. 46. Thousand Oaks: Sage Publications.

Terre Blanche, M., \& Durrheim, K. (2002). Research in practice: Applied methods for the social science. Cape Town: University of Cape Town Press.

Toppinen-Tanner, S., Kalimo, R., \& Mutanen, P. (2002). The process of burnout in white-collar and blue-collar jobs: Eight-year prospective study of exhaustion. Journal of Organizational Behavior, 23(5), 555-570.

Travers, C.J., \& Cooper, C.L. (1993). Mental health and job satisfaction and occupational stress among UK teachers. Work E Stress, 7, 203-219.

Travers, C.J., \& Cooper, C.L. (1996). Teachers under pressure: Stress in teaching. London: Routledge.

Um, M., \& Brown-Standridge, M.D. (1993). Discovering organisational 'rules' that contribute to student stress in social work field placements. Journal of Applied Social Sciences, 17, 157-177.

Um, M., \& Harrison, D.F. (1998). Role stressors, burnout, mediators, and job satisfaction: A stress-strain-outcome model and an empirical test. Social Work Research, 22(2), 100-115.

Valentine, J.C., \& Cooper, H. (2003). Effect size substantive interpretation guidelines: Issues in interpretation of effect sizes. Washington, DC: What Works Clearinghouse.

Van Tonder, C.L. (1997). Workbook on discipline. Unpublished manuscript.

Wengraf, T. (2001). Qualitative research interviewing. London: Sage Publications.

Xanthopoulou, D., Bakker, A.B., Dollard, M.F., Demerouti, E., Schaufeli, W.B., Taris, T.W., \& Scheurs, P.J.G. (2007). When do job demands particularly predict burnout? Journal of Managerial Psychology, 22(8), 766-786.

Zeffane, R., \& McLoughlin, D. (2006). Cooperation and stress. Management Research News, 29(10), 618-631. 